Hydrol. Earth Syst. Sci., 17, 2845-2857, 2013

www.hydrol-earth-syst-sci.net/17/2845/2013/

doi:10.5194/hess-17-2845-2013

(c) Author(s) 2013. CC Attribution 3.0 License.

\title{
Disinformative data in large-scale hydrological modelling
}

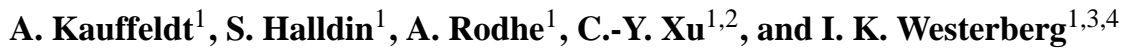 \\ ${ }^{1}$ Department of Earth Sciences, Uppsala University, Uppsala, Sweden \\ ${ }^{2}$ Department of Geosciences, University of Oslo, Oslo, Norway \\ ${ }^{3}$ IVL Swedish Environmental Research Institute, Stockholm, Sweden \\ ${ }^{4}$ Department of Civil Engineering, University of Bristol, Bristol, UK \\ Correspondence to: A. Kauffeldt (anna.kauffeldt@geo.uu.se)
}

Received: 14 December 2012 - Published in Hydrol. Earth Syst. Sci. Discuss.: 14 January 2013

Revised: 1 May 2013 - Accepted: 2 June 2013 - Published: 22 July 2013

\begin{abstract}
Large-scale hydrological modelling has become an important tool for the study of global and regional water resources, climate impacts, and water-resources management. However, modelling efforts over large spatial domains are fraught with problems of data scarcity, uncertainties and inconsistencies between model forcing and evaluation data. Model-independent methods to screen and analyse data for such problems are needed. This study aimed at identifying data inconsistencies in global datasets using a pre-modelling analysis, inconsistencies that can be disinformative for subsequent modelling. The consistency between (i) basin areas for different hydrographic datasets, and (ii) between climate data (precipitation and potential evaporation) and discharge data, was examined in terms of how well basin areas were represented in the flow networks and the possibility of water-balance closure. It was found that (i) most basins could be well represented in both gridded basin delineations and polygon-based ones, but some basins exhibited large area discrepancies between flow-network datasets and archived basin areas, (ii) basins exhibiting too-high runoff coefficients were abundant in areas where precipitation data were likely affected by snow undercatch, and (iii) the occurrence of basins exhibiting losses exceeding the potential-evaporation limit was strongly dependent on the potential-evaporation data, both in terms of numbers and geographical distribution. Some inconsistencies may be resolved by considering subgrid variability in climate data, surface-dependent potentialevaporation estimates, etc., but further studies are needed to determine the reasons for the inconsistencies found. Our results emphasise the need for pre-modelling data analysis to identify dataset inconsistencies as an important first step in any large-scale study. Applying data-screening methods
\end{abstract}

before modelling should also increase our chances to draw robust conclusions from subsequent model simulations.

\section{Introduction}

Large-scale hydrological modelling has become a focal point in hydrological research in recent years and is of fundamental importance for understanding continental and global water balances, impacts of climate and land-use changes, and for water-resources management (e.g. Jung et al., 2012; Li et al., 2012; Mulligan, 2012; Werth and Güntner, 2010). However, hydrological modelling and analysis of large spatial domains is severely constrained by data availability and quality (Arnell, 1999a; Decharme and Douville, 2006; Döll and Siebert, 2002; Fekete et al., 2004; Güntner, 2008; Hunger and Döll, 2008; Peel et al., 2010; Widén-Nilsson et al., 2009). In addition, the modellers' knowledge of the quality and limitations of large-scale datasets is often inevitably inadequate, which restricts the possibility to distinguish informative from disinformative data.

Several previous studies have emphasised the importance of uncertainties and errors associated with input and evaluation data for robust hydrological inference (e.g. Aronica et al., 2006; Freer et al., 2004; McMillan et al., 2012; Montanari and Di Baldassarre, 2012; Thyer et al., 2009). The possibility that data uncertainties may even render combinations of model input and evaluation data disinformative has only recently been discussed (Beven and Westerberg, 2011; Beven et al., 2011). Disinformative data in a hydrological context are data that are physically inconsistent and therefore misleading for model inference and hydrological analyses. 
Beven et al. (2011) use a master recession curve to identify rainfall-runoff events with inconsistent runoff coefficients for a British catchment, i.e. events where the water balance between precipitation input and discharge output is not satisfied, periods that they show are "disinformative" in model evaluation. Westerberg et al. (2011) develop a model evaluation criterion that can be expected to be more robust to some types of moderate disinformation and analyse the effect of disinformative data periods on model inference in a posterior analysis. Kuczera (1996) shows that rating curve errors can "very substantially, indeed massively" corrupt design-flood estimation. When accounting for precipitation errors in calibration of a watershed model, Vrugt et al. (2008) found that the posterior distribution of the parameters and the model predictive uncertainty were significantly affected. Beven and Westerberg (2011) discuss the difficulties in analysing information/disinformation content in hydrological data given multiple sources of epistemic data errors and their interaction with model-structural errors. They highlight the importance of isolating disinformative data periods independent of a model and then excluding them from model calibration and evaluation. Model-independent methods to identify disinformative data and to investigate the effect of different types of disinformation on model inference need to be further developed. These research questions are particularly relevant for global hydrological models (GHMs) that are severely data constrained and where model fit is sometimes only anecdotally described. Substantial correction and tuning factors are reported for GHMs in order to achieve acceptable fit to observed discharge data (e.g. Fekete et al., 1999; Hunger and Döll, 2008; Palmer et al., 2008). At the large scale it is impossible for the modeller to have the same detailed knowledge of the quality and limitations of the modelling datasets as on the local catchment scale. This effectively restricts the possibility to distinguish informative data from disinformative ones, and calls for new types of analysis methods.

GHMs are commonly evaluated against discharge since it represents an aggregated hydrological response of a basin. Selection of basins for calibration/evaluation purposes has previously been done mainly on the grounds of basin size and record-length thresholds (e.g. Döll et al., 2003; Fekete et al., 1999).

Many GHMs operate at a spatial resolution of $0.5^{\circ} \times 0.5^{\circ}$ longitude and latitude, which corresponds to a cell area of approximately $3100 \mathrm{~km}^{2}$ at the Equator (e.g. Arnell, 1999a; Döll et al., 2003; Vörösmarty et al., 1989; Widén-Nilsson et al., 2007, 2009), or even at a coarser resolution (e.g. Hanasaki et al., 2008) and can therefore not be expected to represent small basins very well. The low resolution of GHMs leads to a trade-off between using discharge stations with small basin areas for spatial coverage and excluding them since their representation in coarse flow networks is restricted. Previous global studies have set minimum area thresholds to 9000 (Döll et al., 2003; Kaspar, 2004) and $10000 \mathrm{~km}^{2}$ (Fekete et al., 1999, 2002), and further reduced the number of basins based on interstation-area (i.e. area between river gauges) thresholds of 20000 and $10000 \mathrm{~km}^{2}$, respectively. Hanasaki et al. (2008) use an area threshold of $200000 \mathrm{~km}^{2}$, but their model works at a lower spatial resolution $\left(1^{\circ} \times 1^{\circ}\right.$ longitude and latitude). Yet other studies have limited the evaluation to only a few major river basins (e.g. Nijssen et al., 2001).

Recent development of high-resolution hydrographic datasets such as HydroSHEDS (Lehner et al., 2008) offers the possibility to use high-resolution topographic data in global modelling, e.g. for runoff routing (Gong et al., 2011) and for representation of sub-grid-scale topography in floodplain inundation modelling (Yamazaki et al., 2009, 2011). This has also led to development of new up-scaled datasets and high-resolution basin delineations. This sparks the question whether smaller basins than used in previous studies can be utilised for calibration/evaluation of GHMs and what restrictions to basin size are imposed by input data, since precipitation for longer periods than the last decades is commonly only available at $0.5^{\circ} \times 0.5^{\circ}$ resolution.

The global hydrological-modelling community lacks a methodology to evaluate forcing and calibration data independent of a specific model, which hampers comparisons of results from different models. In order to be right for the right reasons, a global modelling effort should start with an evaluation of data quality and, especially, possible inconsistencies between datasets. This paper presents a basic pre-modelling analysis of large-scale hydrological datasets. The overall goal of the paper was to address the problem of physically inconsistent and therefore disinformative data in large-scale hydrological modelling and to show the importance of a pre-modelling data analysis. The study was performed in two steps. The first step was to evaluate how well basin areas were represented in three gridded $\left(0.5^{\circ} \times 0.5^{\circ}\right)$ hydrography datasets and one high-resolution GIS dataset (derived from 15 arc-second topography) for basins as small as $5000 \mathrm{~km}^{2}$. The second was to analyse and identify inconsistencies between GHM forcing and evaluation data by comparing four precipitation datasets and three potentialevaporation datasets (all gridded at $0.5^{\circ}$ resolution) with observed discharge.

\section{Data}

The hydrographic datasets defining basin areas consisted of both gridded flow networks and a GIS-polygon dataset from the Global Runoff Data Centre (GRDC; Lehner, 2011). The gridded datasets were DDM30 (Döll and Lehner, 2002), STN-30p (Vörösmarty et al., 2000) and an early version (obtained in May 2011) of the datasets developed by $\mathrm{Wu}$ et al. (2012) using the automated dominant-river-tracing algorithm (Wu et al., 2011). This dataset (from here on called DRT) uses a high-resolution baseline, which is a merge between HYDRO1k (USGS EROS, 1996) for high latitudes 
Table 1. Summary of global datasets used in the study.

\begin{tabular}{lcll}
\hline Dataset & $\begin{array}{l}\text { Temporal } \\
\text { resolution }\end{array}$ & $\begin{array}{l}\text { Spatial } \\
\text { resolution }\end{array}$ & Coverage \\
\hline \multicolumn{3}{c}{ Basin delineation } \\
\hline DRT (Wu et al., 2012) & N/A & $0.5^{\circ}$ & Global \\
GIS polygons (Lehner, 2011) & N/A & $\sim 15^{\prime \prime}$ & Selected stations \\
STN-30p (Vörösmarty et al., 2000) & N/A & $0.5^{\circ}$ & Global \\
DDM30 (Döll and Lehner, 2002) & N/A & $0.5^{\circ}$ & Global \\
\hline \multicolumn{5}{c}{ Precipitation } \\
CRU TS 3.10.01 (Harris et al., 2013) & Monthly & $0.5^{\circ}$ & Global/1901-2009 \\
WATCH CRU (Weedon et al., 2011) & Daily & $0.5^{\circ}$ & Global/1901-2001 \\
WATCH GPCC (Weedon et al., 2011) & Daily & $0.5^{\circ}$ & Global/1901-2001 \\
GPCC v6 (Becker et al., 2013) & Monthly & $0.5^{\circ}$ & Global/1901-2010 \\
\hline \multicolumn{2}{c}{ Potential evaporation } & \\
\hline CRU TS 3.10.01 (Harris et al., 2013) & Monthly & $0.5^{\circ}$ & Global/1901-2009 \\
WATCHPM (Weedon et al., 2011) & Daily & $0.5^{\circ}$ & Global/1901-2001 \\
WATCHPT (Weedon et al., 2011) & Daily & $0.5^{\circ}$ & Global/1901-2001 \\
\hline
\end{tabular}

(above $60^{\circ} \mathrm{N}$ ) and HydroSHEDS (Lehner et al., 2008) for the rest of the land surface. Digital elevation data from HydroSHEDS ( $15^{\prime \prime}$ resolution) were used for visualisation purposes. All gridded basin-delineation datasets covered the whole globe, whereas the polygon dataset only covered selected basins (Table 1).

Discharge data were obtained from GRDC in June 2011, at which time the archive held records for 7763 discharge stations worldwide. Record lengths varied considerably between stations. Only monthly data calculated by GRDC from daily records were used because these data contain corrections performed by the providers, such as changes in rating curves, etc. (T. de Couet, GRDC, personal communication, July 2011).

Precipitation datasets included in the study were the Climate Research Unit's freely available CRU TS 3.10.01 climate data (Harris et al., 2013; see Mitchell and Jones, 2005, for version 2.1), GPCC Full Data Reanalysis version 6 (data provided by NOAA/OAR/ESRL PSD, Boulder, Colorado, USA, from www.esrl.noaa.gov/psd/) and both the CRU and the GPCC bias-corrected WATCH forcing data, from here on called WATCH $\mathrm{HRU}_{\mathrm{C}}$ and $\mathrm{WATCH}_{\mathrm{GPCC}}$ (Weedon et al., 2011). The CRU TS 2.1 precipitation dataset is based on ground observations from several sources and each station has been subjected to an iterative homogenisation procedure to detect and correct discontinuities (e.g. caused by changes in instrumentation). Station records have then been converted to relative anomalies compared to the 1961-1990 standard period. The anomalies have been spatially interpolated to a $0.5^{\circ}$ latitude-longitude grid before being combined with 1961-1990 normals from New et al. (1999) to a grid of absolute values (Mitchell and Jones, 2005). Gauge undercatch has not been explicitly corrected, but the 1961-1990 normals were based on both corrected and uncorrected stations, which means some areas are implicitly corrected (Mitchell and Jones, 2005; New et al., 1999). The major difference between the CRU TS 3.10.01 precipitation dataset and the version described in Mitchell and Jones (2005), apart from longer coverage (up to the end of 2009 compared to 2002) and inclusion of new station data, is that no new homogenisation has been performed on CRU TS 3.10.01 (BADC, 2013).

The GPCC precipitation dataset is, just as CRU, a rain-gauge-based dataset derived by spatially interpolating anomalies from quality-controlled station records and combining them with a background climatology to obtain monthly gridded precipitation. However, the number of stations on which the GPCC product is based $(\sim 67200)$ by far exceeds the CRU collection $(\sim 11800)$. The GPCC precipitation dataset does not include corrections for gauge measurement errors (Becker et al., 2013).

As opposed to the CRU and GPCC precipitation datasets, the WATCH precipitation data are not based on observed data, but on the European Centre for Medium-Range Forecasts (ECMWF) $40 \mathrm{yr}$ reanalysis, ERA-40 (Uppala et al., 2005). However, two earlier versions of the CRU (version 2.1) and GPCC (version 4) data products have been used to correct ERA-40 precipitation for known biases (e.g. Hagemann et al., 2005). Bias correction has been done in two steps: (i) the number of wet days has been adjusted to match the observations in CRU if the number of wet days in ERA-40 exceeded the number of wet days in CRU, and (ii) the monthly precipitation totals have been adjusted to match either CRU or GPCC, thereby creating two different precipitation datasets $\left(\mathrm{WATCH}_{\mathrm{CRU}}\right.$ and $\left.\mathrm{WATCH}_{\mathrm{GPCC}}\right)$. Additionally, both precipitation datasets have been corrected for gauge-catch errors using separate average monthly gridded 


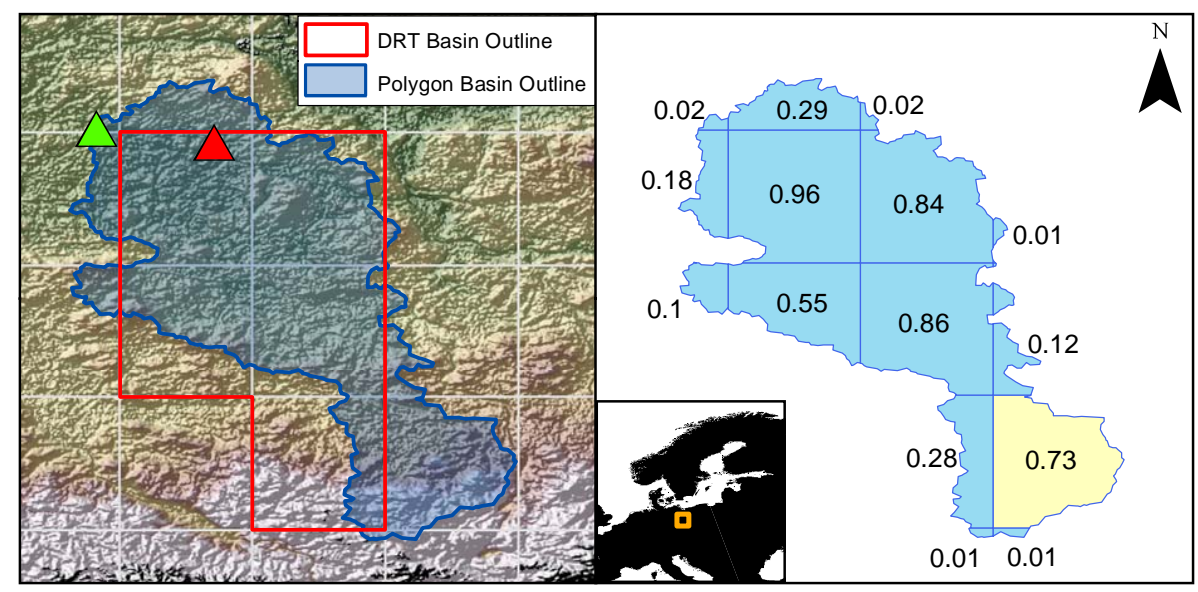

Fig. 1. Example of treatment of gridded climate data for the polygon basin delineations. Basin outline based on DRT and GIS-polygon data for Berlin Mühlendamm UP discharge station on the Spree River $\left(9707 \mathrm{~km}^{2}\right)$ overlaid on $0.5^{\circ}$ climate data grid (left panel). Basin intersections with the climate grid cells labelled with the fraction of the intersecting grid area (right). For each climate grid cell, only the intersecting fraction contributes to the basin average: e.g. for the yellow polygon $73 \%$ of the precipitation falling in the climate grid cell is assumed to fall within the basin. The red triangle indicates the location of the gauge according to the GRDC archive and the green triangle the location after corrections made in the generation of the GIS-polygon dataset.

catch quotients for liquid and solid precipitation from Adam and Lettenmaier (2003). Since the ERA-40 reanalysis product only covers 1958-2001, reordered ERA-40 data have been used for the period 1901-1957 (Weedon et al., 2011).

Potential evaporation is available from the CRU and the WATCH datasets. Both the CRU and the WATCH datasets provide estimates based on the Food and Agricultural Organization (FAO) reference-crop-evaporation equation (Allen et al., 1994). In this version of the Penman-Monteith equation (Monteith, 1965), a hypothetical well-watered reference crop is defined with a height of $0.12 \mathrm{~m}$, an albedo of 0.23 , a surface resistance of $70 \mathrm{~s} \mathrm{~m}^{-1}$ and an aerodynamic resistance based on the crop height and wind speed. The CRU estimates were calculated from monthly gridded values of average/minimum/maximum temperatures, vapour pressure and cloud cover, and fixed monthly wind speeds for the standard period 1961-1990 (Harris et al., 2013). The WATCH FAO Penman-Monteith $\left(\mathrm{WATCH}_{\mathrm{PM}}\right.$ ) dataset is based on 3-hourly bias-corrected ERA-40 data (Weedon et al., 2011). The WATCH dataset also provides estimates based on the Priestley-Taylor equation (Priestley and Taylor, 1972) assuming an albedo of 0.23 and the $\alpha$ factor set to 1.26 (Weedon et al., 2011).

\section{Method}

\subsection{Climate and discharge data}

Climate data were attributed to grid cells defined as land in the basin delineations, but not covered by the climate datasets, in an iterative manner to an average of the closest surrounding cells covered by the climate datasets until all land areas were covered. For the GIS-polygon dataset, the intersections with the half-degree climate-data grid cells were used to calculate the fraction of precipitation and potential evaporation of each cell contributing to the basin (Fig. 1). Sub-grid variability was not taken into account, i.e. precipitation and potential evaporation were assumed to be evenly distributed over each grid cell.

Only data within the common period of the climate datasets (1901-2001) were used in the analysis, and periods for individual basins varied depending on the dischargedata records. The quality control of discharge data in this study was limited to an elimination of clearly erroneous data (i.e. wrongly set nulls such as 999 instead of the correct missing data value of -999). When these appeared in the daily data, the monthly data were also excluded.

\subsection{Hydrography representation of basin areas}

Before the basin-area representation for the different hydrographic datasets could be compared, the discharge stations had to be connected (co-registered) to the gridded flow networks so that each station was assigned to the cell in the hydrography for which the flow-accumulation area (i.e. the sum of all upstream cell areas as defined by the flow network) best corresponded to the basin area in question. For DDM30, co-registrations of GRDC stations and the flow network are available for 1235 stations (Hunger and Döll, 2008) and for STN-30p for 663 stations (Fekete et al., 2002). No coregistrations were available for the DRT dataset, and therefore GRDC stations were co-registered with the gridded hydrography in three steps. Firstly, each station was assigned to the cell corresponding to the coordinates in the GRDC database. Secondly, an automatic re-assignment was made 
if the flow-accumulation area of any of the closest eight surrounding cells better corresponded to the basin area reported by GRDC. And thirdly, all stations exhibiting a relative area difference, $\varepsilon_{\mathrm{A}}$, of more than $10 \%$ were manually inspected and re-assigned if possible. The relative area difference was calculated according to Eq. (1). This measure was adopted since it has been used previously (Döll and Lehner, 2002; Fekete et al., 1999) but under the name "symmetric error". It was termed relative area difference in this study to clarify that no assumption was made about the error distribution.

$\varepsilon_{\mathrm{A}}=\frac{A_{\mathrm{Acc}}-A_{\mathrm{GRDC}}}{\max \left(A_{\mathrm{Acc}}, A_{\mathrm{GRDC}}\right)} \cdot 100 \%$,

$A_{\text {Acc }}$ is the flow-accumulation area of the assigned cell and $A_{\mathrm{GRDC}}$ is the GRDC basin area. Positive (negative) relative area differences mean that calculated basin areas are larger (smaller) than the ones reported to GRDC. The inspection was done in Google Earth by using online map resources and superimposing the flow network on a $1: 10000000$ river network (freely available from www.naturalearthdata.com; accessed on 17 October 2011).

We calculated cell areas for all the gridded hydrographic datasets as quadrangles based on the World Geodetic System 1984 ellipsoid. The relative area differences for all hydrographic datasets were calculated and used to evaluate how well the different datasets represented basin areas in comparison to the areas reported in the GRDC database.

\subsection{Evaluation of consistency between model forcing and evaluation data}

Similarly to Beven et al. (2011), the basic method used in this study was to identify disinformative data as those that violate the conservation equation, i.e. the water balance. In contrast to their event-based approach we analysed the long-term water balance and also analysed data for transgressions of the potential-evaporation limit, similarly to Peel et al. (2010). The change in basin storage can safely be ignored for sufficiently long time periods, except for special cases such as melting glaciers. The water-balance equation can then be simplified to

$P=E_{\mathrm{A}}+R$,

where $P$ is precipitation, $E_{\mathrm{A}}$ actual evaporation and $R$ runoff. For natural basins, runoff should not exceed the precipitation input to the system. Actual evaporation equals the difference between precipitation and runoff and should not exceed potential evaporation $\left(E_{\mathrm{P}}\right)$. These were the fundamental assumptions on which the consistency checks between the forcing data (precipitation and potential evaporation) and the evaluation data (discharge) were based.

All datasets are affected by different types of uncertainties. Estimating them can be difficult because of lack of knowledge about their nature and magnitude, both temporally and spatially. There is a growing literature on quantification of uncertainties connected to hydrological modelling, reviewed by McMillan et al. (2012), concerning magnitudes of observational uncertainties of some key hydrological variables. In the present study, a relative uncertainty of $\pm 10 \%$ was assumed for long-term discharge (resulting in a low, a high and a best (i.e. the original data) estimate for each time series). Climate data were used as given in their original sources, which means that potential evaporation refers to FAO Penman-Monteith reference-crop estimates for $\mathrm{WATCH}_{\mathrm{PM}}$ and CRU and to Priestley-Taylor estimates for $\mathrm{WATCH}_{\mathrm{PT}}$ and, hence that land cover is not explicitly taken into account.

The runoff coefficient (RC), i.e. the quotient of runoff to precipitation, is a measure of how precipitation is partitioned into runoff and evaporation. RCs are often calculated on an event basis and for specific surfaces, but can also be determined as a long-term response characteristic for a basin. Long-term RCs were calculated for low, high and best estimated discharge values, resulting in a high, a low, and a best-estimate RC value for each basin. Hence, the first test of consistency between datasets, that runoff should not exceed precipitation input, stated that RCs should not be higher than one. In reality, a long-term basin RC even close to unity is implausible if the basin definition is correct, since it means that even over several years hardly any flux to the atmosphere would occur. Even in very cold systems losses occur through sublimation from intercepted snow and from snow on the ground (e.g. Strasser et al., 2008). Unity was used as a conservative threshold in this study to avoid classifying datasets as inconsistent based on arbitrary RC thresholds. When based on low estimates of RC values, this threshold could be considered very conservative.

In order to investigate when time periods were "sufficiently" long to determine long-term runoff coefficients, an initial analysis was performed of the variation of RCs with regards to record length. A subset $(n=37)$ was selected of the co-registered GRDC stations with complete data throughout the common period (January 1901-December 2001). For each record length ( 1 to $15 \mathrm{yr}$ of consecutive data), each discharge record was randomly re-sampled 20 times (overlaps occurred) and the runoff coefficient for each sample was calculated. For each basin and sample length, the individual RC estimates were divided by the median RC and plotted for all 37 basins (Fig. 2). It was assumed from the spread in the scatter plot that $10 \mathrm{yr}$ of data sufficed to estimate the long-term runoff coefficients.

The discharge datasets analysed in this paper were not screened for anthropogenic influences (e.g. reservoirs and inter-basin transfers), which means that for some basins the water balance according to Eq. (2) could not be expected to be fulfilled. However, if those influences have an impact then data would still be disinformative in subsequent modelling unless additional data allow for explicit treatment of the anthropogenic influences in the model. 


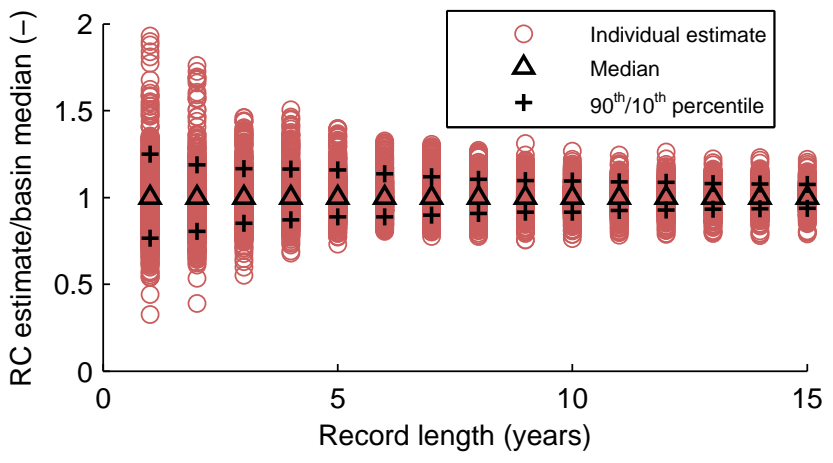

Fig. 2. Variation of runoff-coefficient estimates as a function of record length summarised for 37 basins with long data records. Estimates are standardised by division with the basin median for a given record length.

\section{Results}

\subsection{Hydrography representation of basin area}

Of the 7763 stations available in the GRDC data archive, 245 stations were excluded from the study because of insufficient metadata records, i.e. missing coordinates or basin areas. The remaining 7518 stations with sufficient metadata were registered in the DRT flow network following only the two automatic steps at first. Many stations in the database represented basins smaller than a $0.5^{\circ}$ cell and clear systematic errors because of overestimated areas for these small basins were noticed in this initial stage (Fig. 3). Since manual checking of station locations is very time consuming, the study was limited to basins larger than $5000 \mathrm{~km}^{2}$. This threshold is considerably smaller than those of previous studies but it still meant that most small basins with large relative area differences were excluded. In total, there were 2,177 stations in the archive with basins larger than $5000 \mathrm{~km}^{2}$ for which daily data were available. The remaining stations with relative area differences larger than $10 \%$ were subjected to the third, manual co-registration step. Despite this check, many stations could not be relocated to well-fitting cells and the relative area differences remained large for some stations (Fig. 4b).

Of the stations co-registered in DRT, 558 were also available as co-registered stations in the DDM30 and STN-30p datasets. The relative area differences displayed a markedly larger scatter for STN-30p (standard deviation of $\varepsilon_{\mathrm{A}} 14.3 \%$ ) and DRT $(14.6 \%)$ than for DDM30 (8.9\%) (Fig. 4a-c). None of the datasets showed any general tendency to overor underestimate areas. There was little consistency in the errors between datasets except for a few largely over- and underestimated stations in DDM30 and STN-30p (Fig. 4de). Relative area differences with absolute values over $70 \%$ were observed for all hydrographic datasets.

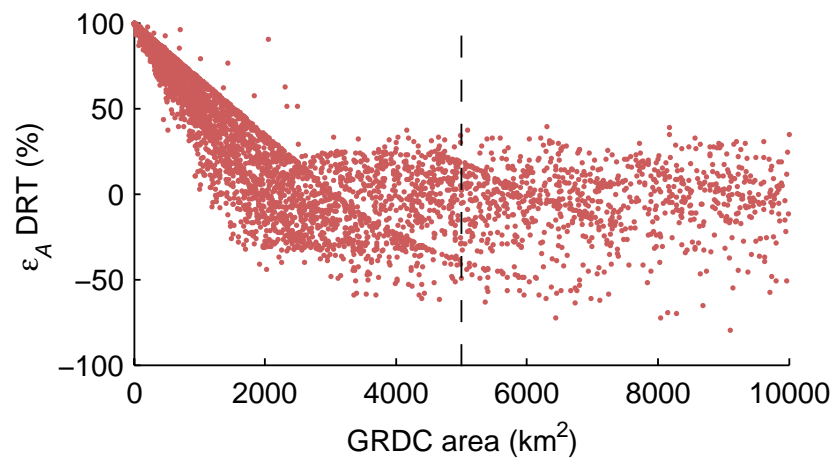

Fig. 3. Relative area difference after automatic relocation for all 7518 GRDC stations with sufficient metadata. The dashed line indicates the $5000 \mathrm{~km}^{2}$ threshold used to select the basins for the rest of the analyses in the study.

The GIS-polygon dataset was compared to the stations coregistered in DRT. Of these 2177 stations, 2005 were available in the GIS dataset. The GIS-polygon-based basin areas showed small errors compared to those of the gridded dataset, but some stations exhibited markedly large errors (Fig. 5a). As before, the errors showed little consistency between datasets (Fig. 5b). Visual inspection of the mapped area discrepancies of the datasets revealed no geographical pattern for any of the datasets.

\subsection{Evaluation of consistency between forcing and evaluation data}

Long-term runoff coefficients could be calculated for 1561 of the 2005 stations that were available in both the polygon dataset and in DRT, given that there should be at least $10 \mathrm{yr}$ of consecutive data. To minimise the effect of area discrepancies, results shown are based on the GIS-polygon basin delineation. The scatter plot of GPCC and CRU precipitation data (Fig. 6a) shows a higher relative difference in precipitation in drier basins. Runoff coefficients for the different precipitation datasets generally show higher relative discrepancies for high runoff coefficients, and implausibly high RCs were mainly found in areas with relatively low precipitation (Fig. 6b-c). The general distributions of RCs did not differ much between the precipitation datasets, and implausibly high runoff coefficients were found for all four datasets even when using the low discharge estimate (Fig. 7). However, RCs higher than one were more common for the CRU and $\mathrm{WATCH}_{\mathrm{CRU}}$ precipitation datasets than for the other two. Basins with high runoff coefficients were almost exclusively located in high-latitude or high-altitude areas (Fig. 8). The majority of the basins with RCs exceeding unity were found in Alaska and north-western Canada.

The second data-consistency test, that actual evaporation given as a residual in Eq. (1) should not exceed potential evaporation, was analysed graphically. Calculated actual evaporation was plotted against potential evaporation (a 
Table 2. Percent of basins (based on the GIS-polygon dataset) exhibiting potential data inconsistencies. Each basin is only accounted for in the worst category that applies to it, e.g. a basin for which the lowest of the actual evaporation estimates exceed the potential evaporation is accounted for in column $E_{\mathrm{AL}}>E_{\mathrm{P}}$ but not $E_{\mathrm{AH}}>E_{\mathrm{P}}$.

\begin{tabular}{llcrrrr}
\hline Precipitation & $\begin{array}{l}\text { Potential } \\
\text { evaporation }\end{array}$ & No remark & $E_{\mathrm{AL}}>E_{\mathrm{P}}$ & $E_{\mathrm{AH}}>E_{\mathrm{P}}$ & $P-R_{\mathrm{L}}<0$ & $P-R_{\mathrm{H}}<0$ \\
\hline CRU & CRU & 85.6 & 4.5 & 2.9 & 3.6 & 3.4 \\
$\mathrm{CRU}$ & WATCH $_{\mathrm{PM}}$ & 71.7 & 12.2 & 9.1 & 3.6 & 3.4 \\
$\mathrm{CRU}$ & WATCH $_{\mathrm{PT}}$ & 62.6 & 19.8 & 10.6 & 3.6 & 3.4 \\
\hline
\end{tabular}
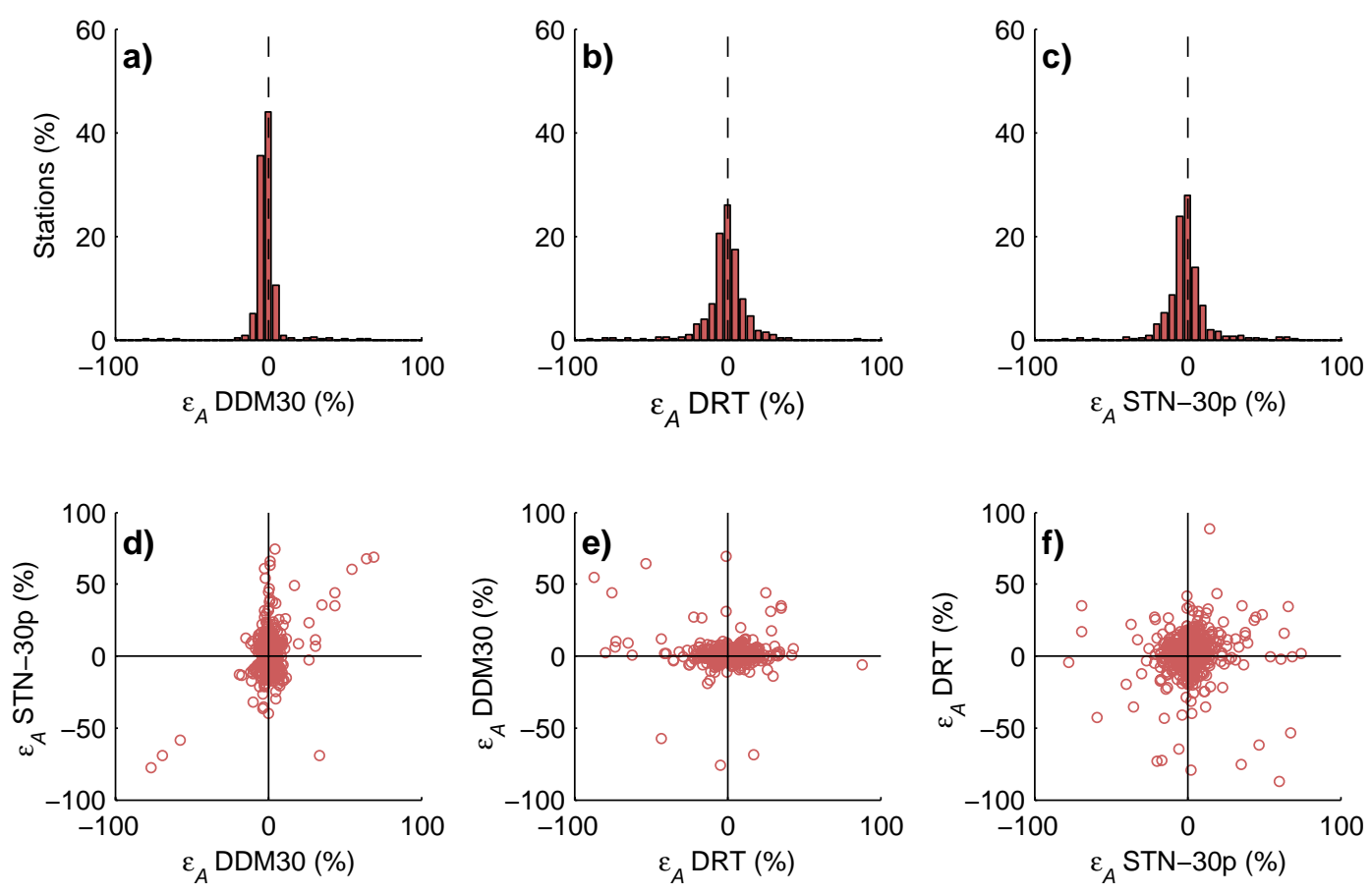

Fig. 4. Histograms of relative area differences for 558 basins with stations registered in the three gridded flow networks: (a) DDM30, (b) DRT and (c) STN-30p. The lower panel shows comparisons of the relative area differences for each basin in the different flow networks.

simplified version of the Budyko, 1974, curve) for all combinations of precipitation and potential-evaporation datasets. The geographical patterns were similar for all combinations (Fig. 9 and Table 2 exemplify the results for the CRU precipitation). Uncertainty in the runoff is represented in colour coding where red represents basins that exhibit actual evaporation $(P-R)$ higher than potential evaporation even for the high discharge estimate (i.e. when the calculated actual evaporation is the lowest, $E_{\mathrm{AL}}$ ) and orange represents basins with actual evaporation higher than the potential-evaporation values for discharge estimates between the low (i.e. when the estimated actual evaporation is the highest, $E_{\mathrm{AH}}$ ) and the high values. One noticeable difference between the different potential-evaporation datasets was the greater frequency of basins exhibiting actual evaporation values higher than the potential-evaporation estimates for the two WATCH datasets compared to the CRU dataset. Implausibly high actual evaporation frequently appeared in the Amazon basin for all three datasets, and for the two WATCH datasets also on the east coast of North America, in Europe, equatorial Africa and South East Asia. Blue dots in Fig. 9 indicate basins for which the actual evaporation was negative (i.e. $\mathrm{RC}>1$ ) for both the high and low discharge estimates and green dots where this occurred only for the low estimates of actual evaporation (i.e. high discharge estimates). The proportions of stations with actual evaporation exceeding potential evaporation or implausibly high RCs were similar for all basin sizes (Fig. 10).

\section{Discussion}

\subsection{Hydrography representation of basin area}

A correct basin area is a prerequisite for a correct water balance. The discrepancies between basin-area estimates in the different hydrographies and the area reported in the GRDC 

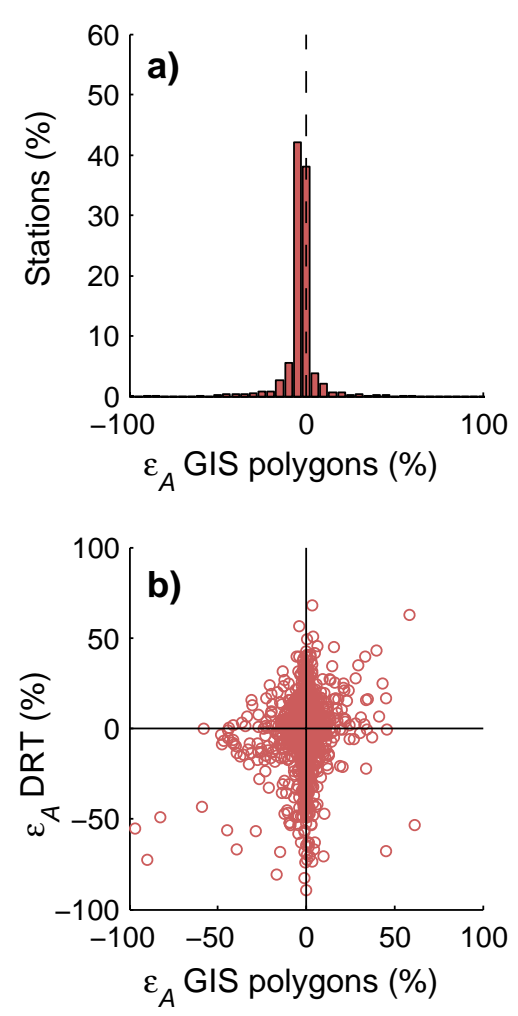

Fig. 5. (a) Relative area differences for 2005 basins based on the GIS-polygon definition and (b) comparison with relative area differences exhibited in DRT.

database are likely attributable both to deficiencies in the basin representations, and to varying quality of the GRDC metadata. The accuracy of the areas given in the archive is not reported by the different data providers (U. Looser, head of GRDC, personal communication, October 2011). The larger scatter observed for STN-30p and DRT compared to DDM30 can likely be explained by the extensive manual corrections of the flow network (35\% of all cells) performed on the latter (Döll and Lehner, 2002). DDM30 outperforms both STN$30 \mathrm{p}$ and DRT in representing basin areas close to the ones reported in GRDC (at least for basins larger than $10000 \mathrm{~km}^{2}$ ). The advantage of DRT over the other two gridded hydrographies would be the possibility to use the high-resolution baseline to derive topographic basin information.

Some of the basin areas reported in the GRDC archive in June 2011 are likely to be different to the ones reported at the time of collection of data for co-registration with STN-30p (Fekete et al., 2002) and DDM30 (Hunger and Döll, 2008) since the GRDC archives have been continuously updated. A comparison of Fig. 5 in Döll and Lehner (2002) and Fig. 4 in this paper showed that at least a few basin areas must have been updated since no absolute relative area differences above $30 \%$ are reported for the DDM30 stations. Hence, the consistency in errors between DDM30 and STN-30p noted for a few largely over- and underestimated basin areas is an indication that those stations had different basin areas reported in the GRDC archive when those co-registrations were done compared to the archive on 15 June 2011 (when data were collected for this study). Changes in the reported areas were also found between October 2010 (the time of data collection for the GIS polygon dataset) and the time when data were collected for this study. The changes were small in most cases, but increases in basin area over $100 \%$ were noted for a few stations.

The GIS-polygon delineation of basins matched basin areas in the GRDC archive well in most cases, but there were some clear discrepancies. Given the extensive manual checks to verify station locations and basin areas during the development of the dataset, it can be argued that the GIS dataset is more likely correct in case of discrepancy. The area discrepancies showed no geographical pattern, even though the GIS dataset is based on a coarser hydrography above $60^{\circ} \mathrm{N}$ and therefore could be expected to perform worse in those areas.

Among the 2005 stations common between the GIS dataset and the stations co-registered with DRT, 584 stations had a basin area of $10000 \mathrm{~km}^{2}$ or less. Of those, $80 \%$ exhibited relative area differences with absolute values less than $25 \%$ in the gridded hydrography compared to $92 \%$ in the GIS delineation. Corresponding figures for relative area differences below $10 \%$ were 45 and $84 \%$, respectively. Hence, many small basin areas were well represented even in the DRT $0.5^{\circ}$ grid. Basin area was the only means of comparison in this study, however, even if the relative area difference is small, it does not mean that the spatial extent (shape) of a basin is correctly described and further checks on this issue could be made. Uncertainty in the spatial representation is likely to be most pronounced for small basins, and when using gridded instead of GIS-polygon hydrographic datasets.

\subsection{Consistency between forcing and evaluation data}

Runoff coefficients greater than unity have been encountered in several global studies (Fekete et al., 2002; Peel et al., 2010; Widén-Nilsson et al., 2009). There could be several reasons for this data mismatch: precipitation underestimation because of poor spatial (and temporal) representativeness of the data and/or measurement errors, discharge-data uncertainties, and anthropogenic influences or subsurface interbasin transfers (Peel et al., 2010). In addition, poor representation of the basin in the up-scaled hydrography could lead to a mismatch, especially for small basins in the gridded hydrographic datasets. However, the effect of hydrography errors should be small for most basins in the GIS-polygon dataset. It was found that the vast majority of basins with implausible runoff coefficients were located in areas where underestimation of precipitation could be caused by snowfall undercatch. Wind-induced solid precipitation undercatch can have a substantial effect on precipitation totals in high-latitude areas (Adam and Lettenmaier, 2003). The geographical patterns were similar for all precipitation datasets, even though the 

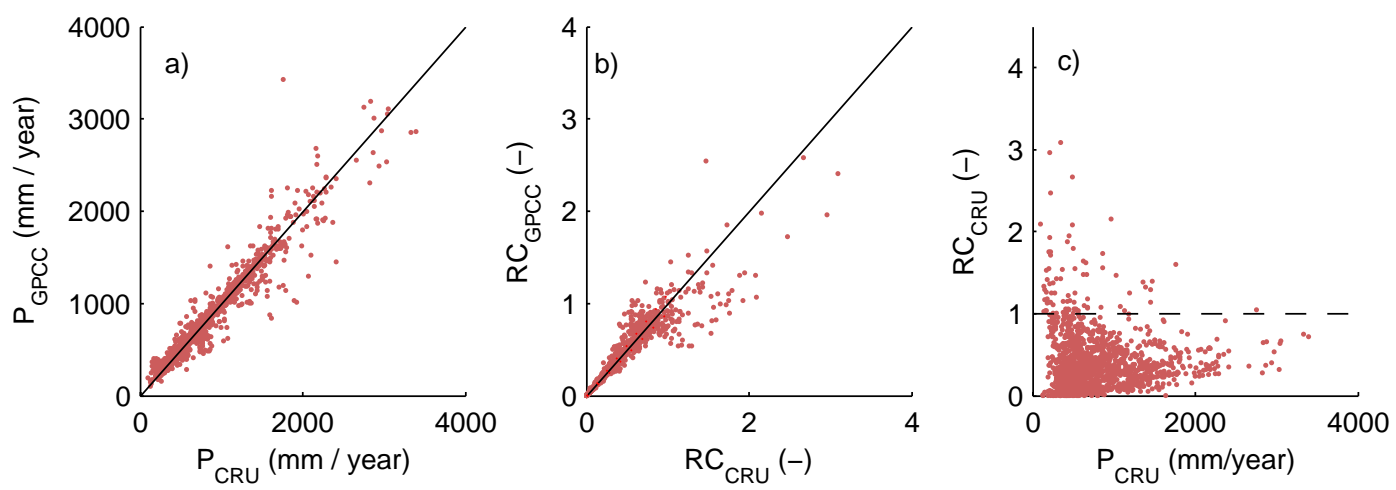

Fig. 6. (a) Relation between GPCC and CRU precipitation, (b) best RC estimates based on GPCC precipitation versus CRU precipitation, and (c) best RC estimates based on CRU precipitation versus CRU precipitation. The $45^{\circ}$ lines indicate the $1: 1$ quotient and the dashed line indicate $\mathrm{RC}=1$.

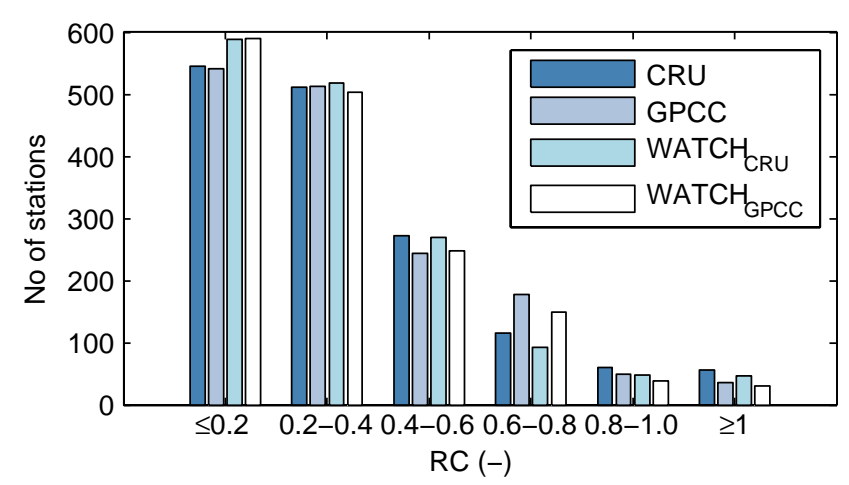

Fig. 7. Distribution of low-estimate RCs for the four precipitation datasets.

WATCH precipitation datasets have been corrected for solid undercatch. Hence, the results indicate that those corrections might not be sufficient, assuming that the discharge data can be trusted.

The evaluation of actual and potential evaporation pointed to further inconsistencies between climate and discharge data. Data inconsistencies led to transgression of the potential-evaporation limit (i.e. $E_{\mathrm{A}}>E_{\mathrm{P}}$ ) in many basins. Peel et al. (2010) report similar issues when analysing a large set $(n=861)$ of basins worldwide using observed station records rather than gridded data. Basins exhibiting actual evaporation higher than potential evaporation were more abundant and appeared in more regions when potential evaporation from the WATCH rather than the CRU dataset was used. Such inconsistencies could be possible for individual basins as a result of e.g. irrigation and inter-basin transfers, not accounted for here. However, a main reason for these inconsistencies is likely limitations of the potentialevaporation estimates.

It is common in GHMs to use potential-evaporation estimates that do not explicitly consider vegetation type (e.g. Döll et al., 2003; Fekete et al., 1999; Widén-Nilsson

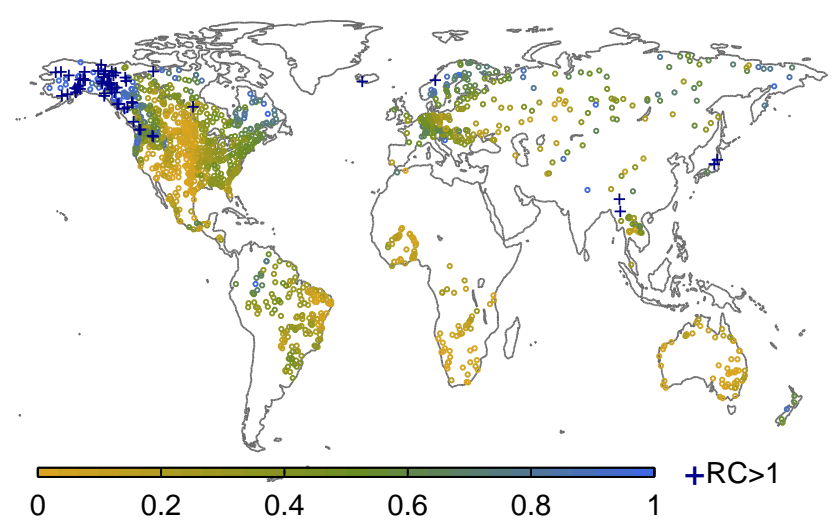

Fig. 8. Spatial pattern of runoff coefficients for CRU precipitation. Circles represent best RC estimates and crosses represent basins with low RC estimates higher than one.

et al., 2007, 2009) or to use crop coefficients only to estimate demand for irrigated crops (e.g. Döll and Seibert, 2002; Wisser et al., 2008, 2010), although some modellers consider vegetation type in the calculation of potential evaporation (e.g. Arnell, 1999b; Gosling and Arnell, 2011). Our results suggest that it could be important to consider land cover since inferred actual evaporation often exceeded potentialevaporation estimates in areas like the Amazon basin where the FAO reference crop estimates might underestimate potential evaporation. It is reasonable to assume that taking land-cover into account could alleviate some of the inconsistencies found. Accurate estimation of potential evaporation on these large scales is a complex task both because of spatial and temporal nonlinearities in the process description and because of the feedback mechanisms between the surface and the atmospheric boundary layer. The resolutions at which data are available at the global scale often prevent considerations of the highly heterogeneous and time-variable nature of many of the variables determining the grid-average potential evaporation. The potential-evaporation datasets used in 

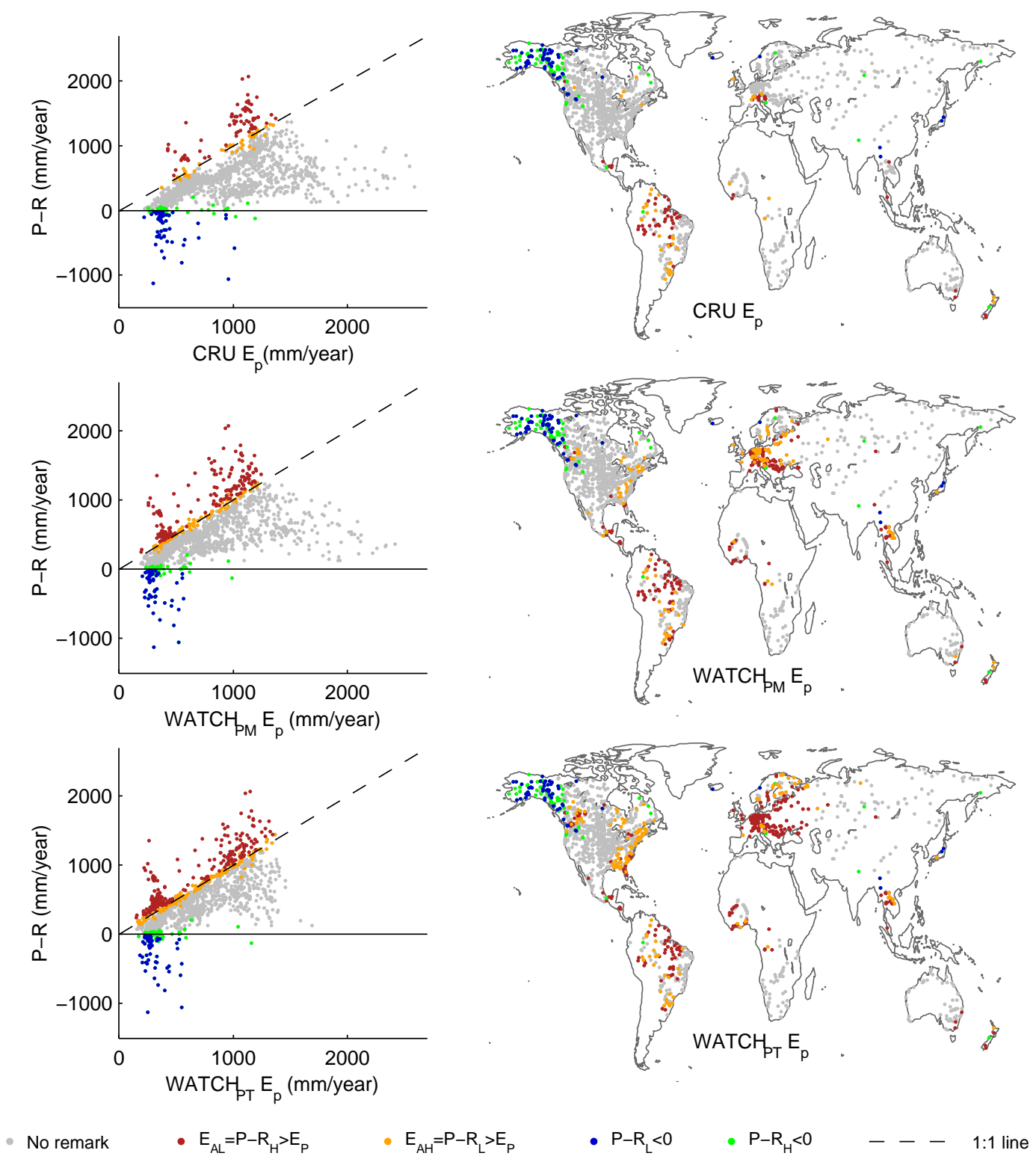

- No remark

$$
\text { - } E_{A L}=P-R_{H}>E_{P} \quad-E_{A H}=P-R_{L}>E_{P}
$$$$
\text { - } \mathrm{P}-\mathrm{R}_{\mathrm{L}}<0 \quad \cdot \mathrm{P}-\mathrm{R}_{\mathrm{H}}<0 \quad---1: 1 \text { line }
$$

Fig. 9. Mean annual actual evaporation (estimated as $P-R$ using CRU precipitation data) versus potential evaporation from CRU, WATCH Penman-Monteith and WATCH Priestley-Taylor (left panel). Potential evaporation is plotted against actual evaporation estimated using the best runoff estimate, i.e. the $y$ value of each dot represents the best evaporation estimate. The colour coding is based on the high runoff estimate $\left(R_{\mathrm{H}}\right.$, giving low estimate of $\left.E_{\mathrm{A}}\right)$ and low runoff estimate $\left(R_{\mathrm{L}}\right.$, giving high estimate of $\left.E_{\mathrm{A}}\right)$ as indicated in the legend. The right panel shows geographical distributions.

this study were all calculated using data of $0.5^{\circ}$ spatial resolution. The real-world variability can be very large within a cell, and because of limited base data, the average cell values may be badly captured both in the input data and in the resulting potential-evaporation estimates. Even if increasing the potential evaporation estimates by $25 \%$, which would correspond to a very high crop factor in all seasons (Allen et al., 1998), many basins still exhibit actual evaporation higher than the potential evaporation.
Sub-grid variability of precipitation can also be large, e.g. in mountainous areas. Taking such variability into account could potentially alleviate inconsistencies found in this study, although solid-precipitation undercatch appears to be a main issue. Sub-grid variability could be important on short timescales, e.g. when modelling runoff timing. We used the climate data as are, since this study was intended as an initial data screening to highlight the need to scrutinise data before a modelling exercise. The discovery of inconsistent data should lead to a search of methods to resolve 


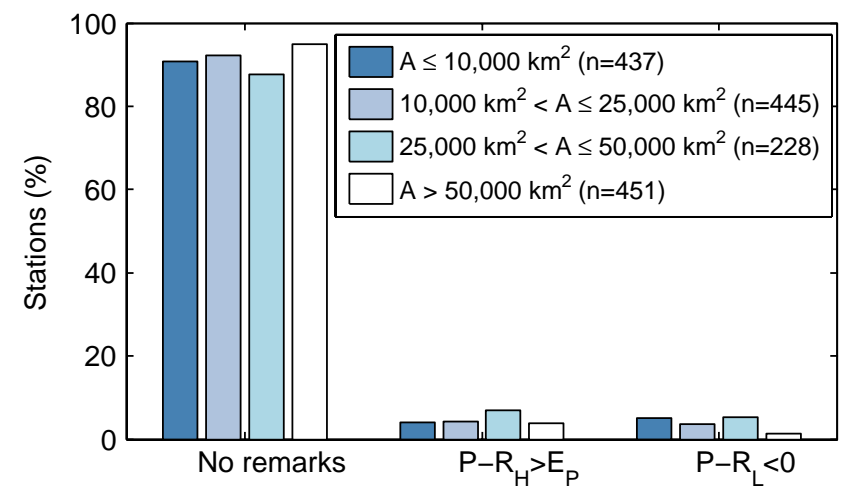

Fig. 10. Basins with and without data inconsistencies, based on CRU precipitation and potential evaporation, in different area categories.

those issues (e.g. gauge-measurement corrections, surfacedependent estimation of potential evaporation, and consideration of anthropogenic influences), and we hope that such studies will follow. As many as $8-43 \%$ of all basins exhibited inconsistencies for the best runoff estimate depending on how the datasets were combined. The corresponding figures were $6-35 \%$ when accounting conservatively for discharge uncertainties and only counting basins falling completely outside of the physically reasonable limits.

These violations to fundamental consistency assumptions pose a serious problem for model calibration and evaluation (Beven and Westerberg, 2011; Beven et al., 2011), and could cause bias in a subsequent model regionalisation. Depending on the evaluation criteria for the calibration, some of these problems could go unnoticed, but model-parameter values could be biased as a result of such long-term inconsistencies. It should be noted that there might be periods of informative data in a dataset even if a long-term average is disinformative. Conversely, datasets found consistent in this analysis might contain data that are disinformative on short timescales. There is a need to develop methods to reliably identify inconsistent events at short timescales for large spatial-scale datasets.

\section{Concluding remarks}

This study has demonstrated that a pre-modelling data analysis should be an important first step in a large-scale hydrological study. Scrutinising input and evaluation data is vital to reveal inconsistencies between datasets and to highlight basins where one should be cautious when making model inferences based on these data. It could be concluded that

- a majority of basins with areas larger than $5000 \mathrm{~km}^{2}$ could be well represented (absolute relative area difference $\leq 25 \%)$ in a $0.5^{\circ} \times 0.5^{\circ}$ longitude-latitude grid. The GIS-polygon delineation derived from a high-resolution hydrographic baseline outperformed the gridded delineation (DRT).

- large and frequent inconsistencies between climate datasets and observed discharge showed clear spatial patterns. Because of this, it was hypothesised that the inconsistencies were mainly caused by limitations in the forcing/evaluation data. Some inconsistencies could also have been caused by anthropogenic influences not considered in this study (e.g. inter-basin transfers, irrigation and reservoirs).

In light of the first point, it could be argued that global hydrological models should use polygon-based basin delineations rather than limiting delineation accuracy to the resolution of the input data, as is common today. This is especially true since large area discrepancies in coarse flow networks can compensate (or aggravate) precipitation-input deficiencies. Even if a model can perform well in such basins, it might be for the wrong reasons. However, this would require development of polygon delineations with full global coverage.

In light of the second point, some inconsistencies may be solved by considering sub-grid variability in climate data, surface-dependent potential-evaporation estimates, etc., but it is likely that inconsistencies for many basins cannot be resolved based on available global data. Further studies will be required to find out the reasons for these inconsistencies and how they affect model inference. A model-independent data analysis, such as the one presented in this study, is a useful tool to identify and analyse inconsistent datasets - therefore enabling more robust conclusions in subsequent hydrological modelling and analyses (Juston et al., 2012).

Acknowledgements. This study has been heavily dependent on provision of global datasets provided by several groups mentioned in the data section. We would like to thank all the groups that have been involved in the development of those datasets. Special thanks are extended to Huan $\mathrm{Wu}$ who provided the early version of the DRT dataset, to Petra Döll who provided the DDM30 dataset, and to the helpful staff at GRDC. The authors are grateful to Keith Beven, Dai Yamazaki and one anonymous reviewer for their constructive comments on the original manuscript.

Edited by: F. Pappenberger

\section{References}

Adam, J. C. and Lettenmaier, D. P.: Adjustment of global gridded precipitation for systematic bias, J. Geophys. Res., 108, 4257, doi:10.1029/2002JD002499, 2003.

Allen, R. G., Smith, M., Pereira, L. S., and Perrier, A.: An update for the calculation of reference evapotranspiration, ICID Bull., 43, 35-92, 1994.

Allen, R. G., Pereira, L. S., Raes, D., and Smith, M.: Crop evapotranspiration - Guidelines for computing crop water requirements, FAO Irrigation and Drainage Paper 56, FAO, Rome, 1998. 
Arnell, N. W.: A simple water balance model for the simulation of streamflow over a large geographic domain, J. Hydrol., 217, 314-335, 1999a.

Arnell, N. W.: Climate change and global water resources, Global Environ. Change, 9, 31-49, 1999b.

Aronica, G. T., Candela, A., Viola, F., and Cannarozzo, M.: Influence of rating curve uncertainty on daily rainfall-runoff model predictions, in: Predictions in Ungauged Basins: Promise and Progress, edited by: Sivapalan, M., Wagener, T., Uhlenbrook, S., Liang, X., Lakshmi, V., Kumar, P., Zehe, E., and Tachikawa, Y., IAHS Publ., 303, 116-124, 2006.

BADC: http://badc.nerc.ac.uk/view/badc.nerc.ac.ukATOMdataent_ 1256223773328276, last access: 8 March 2013.

Becker, A., Finger, P., Meyer-Christoffer, A., Rudolf, B., Schamm, K., Schneider, U., and Ziese, M.: A description of the global land-surface precipitation data products of the Global Precipitation Climatology Centre with sample applications including centennial (trend) analysis from 1901-present, Earth Syst. Sci. Data, 5, 71-99, doi:10.5194/essd-5-71-2013, 2013.

Beven, K. and Westerberg, I.: On red herrings and real herrings: disinformation and information in hydrological inference, Hydrol. Process., 25, 1676-1680, 2011.

Beven, K., Smith, P. J., and Wood, A.: On the colour and spin of epistemic error (and what we might do about it), Hydrol. Earth Syst. Sci., 15, 3123-3133, doi:10.5194/hess-15-31232011, 2011.

Budyko, M. I.: Climate and Life, International Geophysics Series No. 18, edited by: Miller, D. H., Academic Press, London, 508 pp., 1974.

Decharme, D. and Douville, H.: Uncertainties in the GSWP-2 precipitation forcing and their impacts on regional and global hydrological simulations, Clim. Dynam., 27, 695-713, 2006.

Döll, P. and Lehner, B.: Validation of a new global 30-min drainage direction map, J. Hydrol., 258, 214-231, 2002.

Döll, P. and Siebert, S.: Global modeling of irrigation water requirements, Water Resour. Res., 38, 1037-1045, 2002.

Döll, P., Kaspar, F., and Lehner, B.: A global hydrological model for deriving water availability indicators: model tuning and validation, J. Hydrol., 270, 105-134, 2003.

Fekete, B. M., Vörösmarty, C. J., and Grabs, W.: Global composite runoff fields of observed river discharge and simulated water balances, Tech. Rep. No. 22, Global Runoff Data Centre, Koblenz, Germany, 39 pp. plus Annex, 1999.

Fekete, B. M., Vörösmarty, C. J., and Grabs, W.: High-resolution fields of global runoff combining observed river discharge and simulated water balances, Global Biogeochem. Cy., 16, 1042, doi:10.1029/1999GB001254, 2002.

Fekete, B. M., Vörösmarty, C. J., Roads, J. O., and Willmott, C. J.: Uncertainties in precipitation and their impacts on runoff estimates, J. Climate, 17, 294-304, 2004.

Freer, J. E., McMillan, H., McDonnell, J. J., and Beven, K. J.: Constraining dynamic TOPMODEL responses for imprecise water table information using fuzzy rule based performance measures, J. Hydrol., 291, 254-277, doi:10.1016/j.jhydrol.2003.12.037, 2004.

Gong, L., Halldin, S., and Xu, C.-Y.: Global-scale river routing - an efficient time-delay algorithm based on HydroSHEDS high-resolution hydrography, Hydrol. Process., 25, 1114-1128, doi:10.1002/hyp.7795, 2011.
Gosling, S. N. and Arnell, N. W.: Simulating current global river runoff with a global hydrological model: model revisions, validation, and sensitivity analysis, Hydrol. Process., 25, 1129-1145, doi:10.1002/hyp.7727, 2011.

Güntner, A.: Improvement of global hydrological models using GRACE data, Surv. Geophys., 29, 375-397, 2008.

Hagemann, S., Arpe, K., and Bengtsson, L.: Validation of the hydrological cycle of ERA-40, Reports on earth system science, Max Planck Institute, Hamburg, Germany, 2005.

Hanasaki, N., Kanae, S., Oki, T., Masuda, K., Motoya, K., Shirakawa, N., Shen, Y., and Tanaka, K.: An integrated model for the assessment of global water resources - Part 1: Model description and input meteorological forcing, Hydrol. Earth Syst. Sci., 12, 1007-1025, doi:10.5194/hess-12-1007-2008, 2008.

Harris, I., Jones, P. D., Osborn, T. J., and Lister, D. H.: Updated high-resolution grids of monthly climatic observations - the CRU TS3.10 Dataset, Int. J. Climatol., doi:10.1002/joc.3711, in press, 2013.

Hunger, M. and Döll, P.: Value of river discharge data for globalscale hydrological modeling, Hydrol. Earth Syst. Sci., 12, 841861, doi:10.5194/hess-12-841-2008, 2008.

Jung, G., Wagner, S., and Kunstmann, H.: Joint climate-hydrology modeling: an impact study for the data-sparse environment of the Volta Basin in West Africa, Hydrol. Res., 43, 231-248, 2012.

Juston, J. M., Kauffeldt, A., Quesada Montano, B., Seibert, J., Beven, K., and Westerberg, I.: Smiling in the rain: Seven reasons to be positive about uncertainty in hydrological modelling, Hydrol. Process., 27, 1117-1122, doi:10.1002/hyp.9625, 2012.

Kaspar, F.: Entwicklung und unsicherheitanalyse eines globalen hydrologischen modells, Ph.D. Thesis, Department of Natural Sciences, Kassel University, Kassel, Germany, 139 pp., 2004.

Kuczera, G.: Correlated rating curve error in flood frequency inference, Water Resour. Res., 32, 2119-2127, 1996.

Lehner, B.: Derivation of watershed boundaries for GRDC gauging stations based on the HydroSHEDS drainage network, Tech. Rep. No. 41, Global Runoff Data Centre, Koblenz, Germany, 12 pp., 2011.

Lehner, B., Verdin, K., and Jarvis, A.: New global hydrography derived from spaceborne elevation data, Eos. Trans. AGU, 89, 93, 2008.

Li, L., Ngongondo, C. S., Xu, C.-Y., and Gong, L.: Comparison of the global TRMM and WFD precipitation datasets in driving a large-scale hydrological model in Southern Africa, Hydrol. Res., doi:10.2166/NH.2012.175, in press, 2012.

McMillan, H., Krueger, T., and Freer, J.: Benchmarking observational uncertainties for hydrology: rainfall, river discharge and water quality, Hydrol. Process., 26, 4078-4111, doi:10.1002/HYP.9384, 2012.

Mitchell, T. D. and Jones, P. D.: An improved method of constructing a database of monthly climate observations and associated high-resolution grids, Int. J. Climatol., 25, 693-712, 2005.

Montanari, A. and Di Baldassarre, G.: Data errors and hydrological modelling: The role of model structure to propagate observation uncertainty, Adv. Water Resour., 51, 498-504, doi:10.1016/j.advwatres.2012.09.007, 2012.

Monteith, J. L.: Evaporation and environment, Sym. Soc. Exp. Bio., 19, 205-234, 1965. 
Mulligan, M.: WaterWorld: a self-parameterising, physically-based model for application in data-poor but problem-rich environments globally, Hydrol. Res., doi:10.2166/nh.2012.217, in press, 2012.

New, M., Hulme, M., and Jones, P.: Representing twentieth-century space-time climate variability, Part I: Development of a 1961-90 mean monthly terrestrial climatology, J. Climate, 12, 829-856, 1999.

Nijssen, B., O’Donnell, G., Hamlet, A., and Lettenmaier, D.: Hydrologic sensitivity of global rivers to climate change, Climatic Change, 50, 143-175, 2001.

Palmer, M. A., Reidy Liermann, C. A., Nilsson, C., Flörke, M., Alcamo, J., Lake, P. S., and Bond, N.: Climate change and the world's river basins: anticipating management options, Front. Ecol. Environ., 6, 81-89, 2008.

Peel, M. C., McMahon, T. A., and Finlayson, B. L.: Vegetation impact on mean annual evapotranspiration at a global catchment scale, Water Resour. Res., 46, W09508, doi:10.1029/2009WR008233, 2010.

Priestley, C. H. B. and Taylor, R. J.: On the assessment of surface heat flux and evaporation using large-scale parameters, Mon. Weather Rev., 100, 81-92, 1972.

Strasser, U., Bernhardt, M., Weber, M., Liston, G. E., and Mauser, W.: Is snow sublimation important in the alpine water balance?, The Cryosphere, 2, 53-66, doi:10.5194/tc-2-53-2008, 2008.

Thyer, M., Renard, B., Kavetski, D., Kuczera, G., Franks, S. W., and Srikanthan, S.: Critical evaluation of parameter consistency and predictive uncertainty in hydrological modeling: A case study using Bayesian total error analysis, Water Resour. Res., 45, W00b14, doi:10.1029/2008WR006825, 2009.

Uppala, S. M., Kållberg, P. W., Simmons, A. J., Andrae, U., Bechtold, V. D. C., Fiorino, M., Gibson, J. K., Haseler, J., Hernandez, A., Kelly, G. A., Li, X., Onogi, K., Saarinen, S., Sokka, N., Allan, R. P., Andersson, E., Arpe, K., Balmaseda, M. A., Beljaars, A. C. M., Berg, L. V. D., Bidlot, J., Bormann, N., Caires, S., Chevallier, F., Dethof, A., Dragosavac, M., Fisher, M., Fuentes, M., Hagemann, S., Hólm, E., Hoskins, B. J., Isaksen, L., Janssen, P. A. E. M., Jenne, R., Mcnally, A. P., Mahfouf, J.-F., Morcrette, J.-J., Rayner, N. A., Saunders, R. W., Simon, P., Sterl, A., Trenberth, K. E., Untch, A., Vasiljevic, D., Viterbo, P., and Woollen, J.: The ERA-40 re-analysis, Q. J. Roy. Meteorol. Soc., 131, 2961-3012, doi:10.1256/qj.04.176, 2005.

USGS EROS, HYDRO1k Elevation Derivative Database: http://eros.usgs.gov/\#/FindData/Products_andDataAvailable/ gtopo30/hydro (last access: 30 September 2012), 1996.

Vörösmarty, C. J., Moore III, B., Grace, A. L., Gildea, M. P., Melillo, J. M., Peterson, B. J., Rastetter, E. B., and Steudler, P. A.: Continental scale models of water balance and fluvial transport: An application to South America, Global Biogeochem. Cy., 3, 241-265, 1989.

Vörösmarty, C. J., Fekete, B. M., Meybeck, M., and Lammers, R. B.: Global system of rivers: Its role in organizing continental land mass and defining land-to-ocean linkages, Global Biogeochem. Cy., 14, 599-621, 2000.
Vrugt, J. A., ter Braak, C. J. F., Clark, M. P., Hyman, J. M., and Robinson, B. A.: Treatment of input uncertainty in hydrologic modeling: Doing hydrology backward with Markov chain Monte Carlo simulation, Water Resour. Res., 44, W00B09, doi:10.1029/2007WR006720, 2008.

Weedon, G. P., Gomes, S., Viterbo, P., Shuttleworth, W. J., Blyth, E., Österle, H., Adam, J. C., Bellouin, N., Boucher, O., and Best, M.: Creation of the WATCH forcing data and its use to assess global and regional reference crop evaporation over land during the twentieth century, J. Hydrometeorol., 12, 823-848, 2011.

Werth, S. and Güntner, A.: Calibration analysis for water storage variability of the global hydrological model WGHM, Hydrol. Earth Syst. Sci., 14, 59-78, doi:10.5194/hess-14-59-2010, 2010.

Westerberg, I. K., Guerrero, J.-L., Younger, P. M., Beven, K. J., Seibert, J., Halldin, S., Freer, J. E., and Xu, C.-Y.: Calibration of hydrological models using flow-duration curves, Hydrol. Earth Syst. Sci., 15, 2205-2227, doi:10.5194/hess-15-22052011, 2011.

Widén-Nilsson, E., Halldin, S., and Xu, C.-Y.: Global water-balance modelling with WASMOD-M: Parameter estimation and regionalisation, J. Hydrol., 340, 105-118, 2007.

Widén-Nilsson, E., Gong, L., Halldin, S., and Xu, C.-Y.: Model performance and parameter behavior for varying time aggregations and evaluation criteria in the WASMOD-M global water balance model, Water Resour. Res., 45, W05418, doi:10.1029/2007WR006695, 2009.

Wisser, D., Frolking, S., Douglas, E. M., Fekete, B. M., Vörösmarty, C. J., and Schumann, A. H.: Global irrigation water demand: Variability and uncertainties arising from agricultural and climate data sets, Geophys. Res. Lett., 35, L24408, doi:10.1029/2008GL035296, 2008.

Wisser, D., Fekete, B. M., Vörösmarty, C. J., and Schumann, A. H.: Reconstructing 20th century global hydrography: a contribution to the Global Terrestrial Network-Hydrology (GTN-H), Hydrol. Earth Syst. Sci., 14, 1-24, doi:10.5194/hess-14-1-2010, 2010.

Wu, H., Kimball, J. S., Mantua, N., and Stanford, J.: Automated upscaling of river networks for macroscale hydrological modeling, Water Resour. Res., 47, W03517, doi:10.1029/2009WR008871, 2011.

Wu, H., Kimball, J. S., Li, H., Huang, M., Leung, L. R., and Adler, R. F.: A new global river network database for macroscale hydrologic modeling, Water Resour. Res., 48, W09701, doi:10.1029/2012WR012313, 2012.

Yamazaki, D., Oki, T., and Kanae, S.: Deriving a global river network map and its sub-grid topographic characteristics from a fine-resolution flow direction map, Hydrol. Earth Syst. Sci., 13, 2241-2251, doi:10.5194/hess-13-2241-2009, 2009.

Yamazaki, D., Kanae, S., Kim, H., and Oki, T.: A physically based description of floodplain inundation dynamics in a global river routing model, Water Resour. Res., 47, W04501, doi:10.1029/2010WR009726, 2011. 